\title{
An open-label trial of tomoxetine in pediatric attention deficit hyperactivity disorder.
}

\author{
Christopher J. Kratochvil \\ University of Nebraska Medical Center, ckratoch@unmc.edu \\ Daryl Bohac \\ University of Nebraska Medical Center \\ Martin Harrington \\ University of Nebraska Medical Center \\ Natalie Baker \\ University of Nebraska Medical Center \\ Diane E. May \\ University of Nebraska Medical Center, dmay@unmc.edu
}

See next page for additional authors

Tell us how you used this information in this short survey.

Follow this and additional works at: https://digitalcommons.unmc.edu/com_psych_articles

Part of the Psychiatry Commons

\section{Recommended Citation}

Kratochvil, Christopher J.; Bohac, Daryl; Harrington, Martin; Baker, Natalie; May, Diane E.; and Burke, William J., "An open-label trial of tomoxetine in pediatric attention deficit hyperactivity disorder." (2001). Journal Articles: Psychiatry. 13.

https://digitalcommons.unmc.edu/com_psych_articles/13

This Article is brought to you for free and open access by the Psychiatry at DigitalCommons@UNMC. It has been accepted for inclusion in Journal Articles: Psychiatry by an authorized administrator of DigitalCommons@UNMC. For more information, please contact digitalcommons@unmc.edu. 


\section{Authors}

Christopher J. Kratochvil, Daryl Bohac, Martin Harrington, Natalie Baker, Diane E. May, and William J. Burke 


\title{
An Open-Label Trial of Tomoxetine in Pediatric Attention Deficit Hyperactivity Disorder
}

\author{
CHRISTOPHER J. KRATOCHVIL, M.D., DARYL BOHAC, Ph.D., \\ MARTIN HARRINGTON, M.D., NATALIE BAKER, M.D., DIANE MAY, R.N., M.A., \\ and WILLIAM J. BURKE, M.D.
}

\begin{abstract}
Objective: To collect pilot data assessing the safety, tolerability, and efficacy of tomoxetine, a nonstimulant norepinephrine enhancer, in pediatric attention deficit hyperactivity disor$\operatorname{der}$ (ADHD).

Methods: An open-label trial of tomoxetine in pediatric ADHD was conducted as part of a multisite clinical trial. Following a baseline assessment, an ascending dose titration was completed during 10 weekly visits.

Results: Ten subjects were enrolled at baseline, with eight completing the study. Seven of the eight remaining subjects met efficacy criteria. Significant decreases in symptom severity ratings by parents and study investigators were found. The medication was well tolerated, with transient appetite suppression the most frequently reported side effect. However, subjects' weights remained stable across study visits.

Discussion: These preliminary findings suggest that tomoxetine may hold promise as a treatment for pediatric ADHD.
\end{abstract}

\section{INTRODUCTION}

A TTENTION DEFICIT HYPERACTIVITY DISORDER (ADHD) is one of the most common disorders of childhood, with a prevalence rate of 3-5\% (Tannock 1998), yet there are only three primary psychopharmacological interventions for ADHD: methylphenidate, dextroamphetamine, and d,l-amphetamine. Although the stimulants are quite effective, some youth do not respond, whereas others are never initiated on stimulants due to concerns regarding treatment with a controlled substance. Additionally, some children treated with these stimulants frequently suffer from diminished appetite, weight loss, insomnia, exacerbation of tics, stomach aches, headaches, irritability, and mood lability. Thus, there is a clear need for alternatives to current treatments of ADHD.

Recently Spencer and colleagues reported on the use of a novel medication, tomoxetine, in the treatment of adult ADHD (Spencer et al. 1998). Tomoxetine enhances norepinephrine function through highly selective blockade of the presynaptic norepinephrine transporter and has low affinity for other neuronal trans-

Department of Psychiatry, University of Nebraska Medical Center, Omaha, Nebraska.

This study was supported in part by a grant from Lilly Research Laboratories. 
porters or neurotransmitter receptor sites. Spencer et al. found that tomoxetine was well tolerated and effective in the treatment of adult ADHD, with 11 of 21 subjects showing improvement after receiving tomoxetine compared to only 2 of 21 who received placebo. More recently, preliminary results from a pair of double-blind placebo-controlled trials indicated that tomoxetine was well tolerated and effective in treating pediatric ADHD (Heiligenstein et al. 2000). This article reports additional evidence of tomoxetine's effectiveness based on one site's results from the open-label phase of a separate ongoing investigation involving 198 subjects at 24 sites.

\section{METHODS}

The objective of this study was to collect pilot data assessing the safety, tolerability, and efficacy of this agent in a pediatric population with ADHD. The Attention Deficit/Hyperactivity Disorder Rating Scale-IVParent Version (ADHDRS-IV-P) was utilized as a primary efficacy measure (DuPaul 1991). The ADHDRSIV-P is an 18-item scale with 1 item for each of the 18 symptoms contained in the Diagnostic and Statistical Manual of Mental Disorders, fourth edition (DSM-IV; American Psychiatric Association 1994) diagnostic criteria for ADHD. It was utilized as a clinician-administered, semistructured parent interview at each study visit to assess symptom severity for the prior week. The ADHDRS-IV-P Total Score was used in all statistical analyses. Two secondary measures of efficacy were employed in this study. First, study physicians completed the Clinical Global Impressions-ADHD-Improvement (CGI-ADHD-I; Guy 1967) ratings at study visits 3 through 12. The CGI-ADHD-I is a single-item clinician rating of the total change in the patient's ADHD symptoms since the beginning of treatment. Second, the Conners' Parent Rating ScaleRevised: Short Form (CPRS-R:S; Conners et al. 1998), a 27-item scale designed to assess problem behaviors related to ADHD, was completed by parents at study visits 1, 2, and 12. The ADHD Index score from the CPRS-R:S was used as the dependent measure in all statistical analyses.

All subjects enrolling in the study met DSM-IV criteria for ADHD (American Psychiatric Association 1994). After a complete description of the study to the subjects, written informed consent was obtained from the parents and assent was obtained from the subjects. Following baseline assessment, subjects completed an open-label ascending dose titration of tomoxetine. The titration schedule was based on tolerability and clinical response.

Subjects were defined as treatment responders if they had both a score of 1 or 2 (very much or much improved) on the CGI-ADHD-I and at least a 25\% decrease in ADHDRS-IV-P total score by visit 12. One subject had CGI-ADHD-I scores of 1 for three consecutive visits (i.e., visits 6 through 8). This subject's final visit data were carried forward into the remaining visits for all statistical analyses.

Visits occurred weekly for a total of 10 weeks on medication. Vital signs, weight, EKGs, and chemical and hematological profiles were repeated serially during the study. Safety monitoring included documentation of adverse events at every visit. Adverse events were identified utilizing spontaneous open-ended questioning. The Barkley Behavior and Adverse Events Questionnaire-Modified (BBAEQ-M) was also used to review potential untoward effects systematically.

\section{RESULTS}

Ten males with ADHD (nine Whites and one Hispanic, 9-14 years of age) were enrolled in the study. The group had an average estimated IQ of 104.4 ( $\mathrm{SD}=16.6$, range $=85-130$ ) on a four-subtest short form of the Wechsler Intelligence Scale for Children, third edition (WISC-III; Wechsler 1991). Similarly, subjects obtained Wide Range Achievement Test, third edition (Wilkinson 1993), average scores of 100.9 $(\mathrm{SD}=15.48$, range $=79-131)$ for reading, $102.6(\mathrm{SD}=18.26$, range $=81-139)$ for spelling, and 91.6 $(\mathrm{SD}=8.93$, range $=81-107)$ for arithmetic. The average weight of the subjects was $43.2 \mathrm{~kg}$ and ranged from 30.5 to $65.3 \mathrm{~kg}$. At baseline, all subjects had an ADHDRS-IV-P score at least 1.5 standard deviations from the mean for their age and sex. Of the 10 subjects treated with tomoxetine, one withdrew because of a rash, one was discontinued due to noncompliance, and eight completed the scheduled visits. Of these eight 


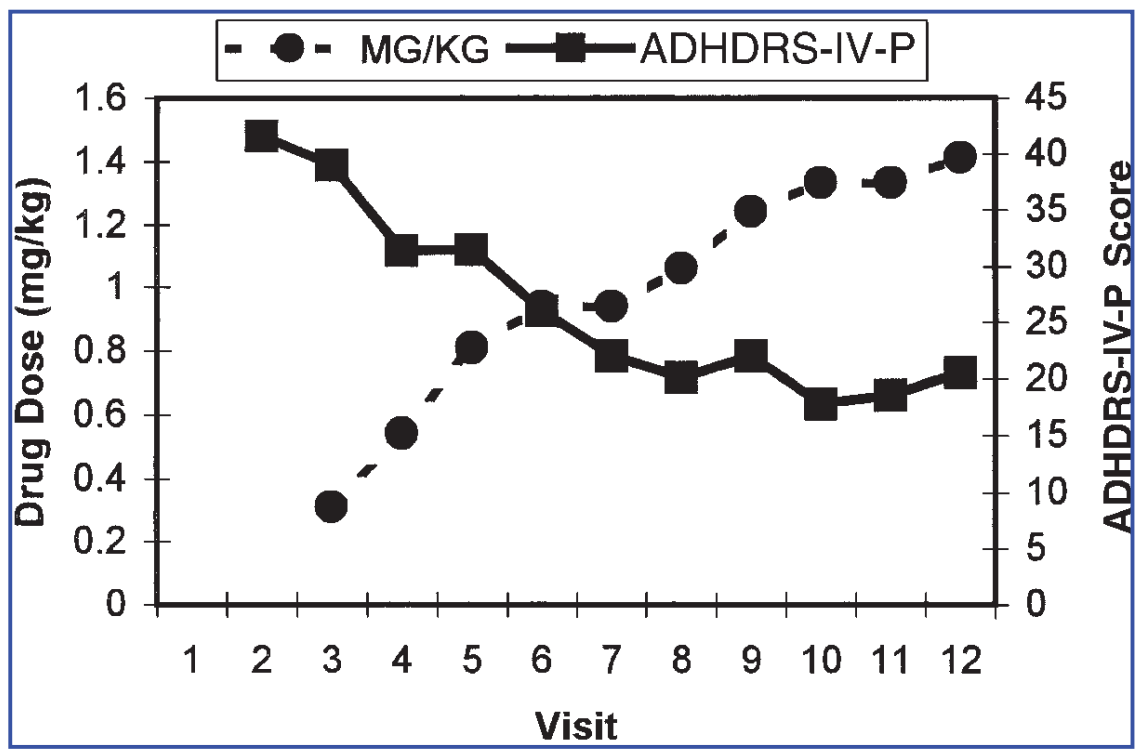

FIG. 1. Dose level by symptom severity across visits. ADHDRS-IV-P = Attention Deficit/Hyperactivity Disorder Rating Scale-IV-Parent Version.

subjects, seven met criteria for ADHD, combined subtype, and one for inattentive subtype. In addition to the ADHD diagnoses, one subject met criteria for a simple phobia, one for generalized anxiety disorder, and four for oppositional defiant disorder. At endpoint, seven of eight subjects met efficacy criteria of a $25 \%$ or greater reduction in the ADHDRS-IV-P total score and a CGI-ADHD-I score of 1 or 2 . The one nonresponder met criteria for ADHD, combined subtype, with no comorbid diagnosis.

Scores from the efficacy measures were subjected to repeated measures analysis of variance. For ADHDRS-IV-P ratings across study visits, the change in scores was significant, $F(9,63)=5.65, p=0.0001$, and in the expected direction with severity ratings decreasing over the course of the study. Clinician ratings of improvement using the CGI-ADHD-I were also significantly different across visits, $F(9,63)=5.21$, $p=0.0001$. The relationship between mean ADHD severity ratings and mean $\mathrm{mg} / \mathrm{kg}$ dose levels across study visits is represented in Fig. 1. A plot of mean CGI-ADHD-I scores by mean dose level resulted in curves nearly paralleling those seen in Fig. 1.

CPRS-R:S mean scores across visits were also examined using repeated measures analysis of variance (Table 1). A significant effect was determined across visits 1,2 , and $12, F(2,14)=19.25, p=0.0001$. Bonferroni-corrected, post-hoc univariate $F$ tests demonstrated that the effect was between visits 2 and 12, $F(1,7)=22.64, p=0.002$. No significant difference was found between rating scale scores on visit 1 (screening) and visit 2 (baseline), during which the subjects received no drug.

Medication was well tolerated throughout the 10 weeks of treatment. One subject withdrew due to a rash, believed to be medication induced as it reoccurred when the subject was rechallenged with tomoxetine. Six

Table 1. Pre- and Posttreatment Scores for Efficacy Measures

\begin{tabular}{|c|c|c|c|c|c|}
\hline & \multicolumn{2}{|c|}{ Baseline } & \multicolumn{2}{|c|}{ Posttreatment } & \multirow[b]{2}{*}{$\mathrm{p}$} \\
\hline & Mean & $S D$ & Mean & $S D$ & \\
\hline ADHDRS-IV-P & 41.6 & 10.7 & 20.5 & 12.6 & 0.0001 \\
\hline CPRS-R : S & 60.0 & 14.0 & 29.8 & 18.1 & 0.0001 \\
\hline CGI-ADHD-I ${ }^{\mathrm{a}}$ & 3.6 & 0.9 & 1.6 & 0.7 & 0.0001 \\
\hline
\end{tabular}

ADHDRS-IV-P = Attention Deficit/Hyperactivity Disorder Rating Scale-IV-Parent Version; CGI-ADHD-I = Clinical Global Impressions-ADHD-Improvement; CPRS-R : S = Conners' Parent Rating Scale-Revised Short Form.

${ }^{a}$ CGI-ADHD-I ratings were first obtained at study visit 3 , at which time subjects had been on medication for 1 week. 
of 10 subjects reported transient appetite suppression of mild to moderate severity. For the 10 subjects who met entry criteria, weight remained stable across study visits when comparing baseline weight $(\mathrm{mean}=$ $43.23, \mathrm{SD}=10.66 \mathrm{~kg}$ ) to weight at last study visit (mean $=42.08, \mathrm{SD}=9.98 \mathrm{~kg}$ ), using last-observationcarried-forward analysis $(t=-1.75, d f=9, p=0.11)$. Other transient adverse events included gastrointestinal symptoms (4 children), irritability (3), fatigue (3), epistasis (1), dizziness (1), dry mouth (1), nightmares (1), headache (1), and heart palpitations (1). There were no spontaneous reports of insomnia. Investigators treated the transient adverse events symptomatically with no further medical intervention required.

\section{DISCUSSION}

The initial pilot data suggest that tomoxetine may be a useful intervention for pediatric ADHD. These preliminary findings are important in that they indicate a norepinephrine enhancer may be effective in treating this disorder. Tomoxetine may also represent an alternative for those patients who fail to respond to one of the primary psychopharmacological interventions for ADHD.

Despite the limitations of this study, which include a small sample size and an open-label design, these initial results are promising. The sample size is currently being addressed in larger multicenter studies. Heiligenstein et al.'s (2000) preliminary data from two randomized clinical trials in children with ADHD, which suggested that tomoxetine is safe, well tolerated, and leads to a significant reduction in ADHD symptoms, are consistent with our findings. Our results and emerging data from other trials suggest that tomoxetine may hold promise as a treatment for pediatric ADHD.

\section{REFERENCES}

American Psychiatric Association: Diagnostic and Statistical Manual of Mental Disorders, 4th ed. (DSM-IV). Washington, DC, American Psychiatric Association, 1994.

Conners CK, Sitarenios G, Parker JD, Ebstein JN: The revised Conners' Parent Rating Scale (CPRS-R): Factor structure, reliability, and criterion validity. J Abnorm Child Psychol 25:257-268, 1998.

DuPaul G: Parent and teacher ratings of ADHD symptoms: Psychometric properties in a community-based sample. J Clin Child Psychol 20:245-253, 1991.

Guy W: CGI, Clinical Global Impression. In: ECDEU Assessment Manual for Psychopharmacology, revised. U.S. Department of Health, Education, and Welfare, Washington, D.C. 1967.

Heiligenstein JH, Spencer TJ, Faries DE, Biederman J, Kratochvil C, Conners CK: Efficacy of tomoxetine vs. placebo in pediatric outpatients with ADHD. Poster presentation at the 47th Annual Meeting of the American Academy of Child and Adolescent Psychiatry, New York, October 2000.

Spencer T, Biederman J, Wilens T, Prince J, Hatch M, Jones J, Harding M, Faraone SV, Seidman L: Effectiveness and tolerability of tomoxetine in adults with attention deficit hyperactivity disorder. Am J Psychiatry 155:693-695, 1998.

Tannock R: Attention deficit hyperactivity disorder: Advances in cognitive, neurobiological, and genetic research. J Child Psychol Psychiatry 39:65-99, 1998.

Wechsler D: Wechsler Intelligence Scale for Children, 3rd ed. San Antonio (Texas), Psychological Corporation, 1991. Wilkinson GS: Wide Range Achievement Test, 3rd ed. Administration Manual. Wilmington (Deleware), Wide Range, Inc., 1993.

Address reprint requests to: Christopher J. Kratochvil, M.D. 985581 Nebraska Medical Center Omaha, NE 68191-5581

E-mail: ckratoch@unmc.edu 


\section{This article has been cited by:}

1. Andrew T. McAfee, Joan Landon, Meghan Jones, Mark E. Bangs, Nayan Acharya, Ken Hornbuckle, Judy Wong. 2013. A cohort study of the risk of seizures in a pediatric population treated with atomoxetine or stimulant medications. Pharmacoepidemiology and Drug Safety 22:4, 386-393. [CrossRef]

2. Soochurl Cho, Soyoung Irene Lee, Hanik Yoo, Dong Ho Song, Dong-Hyun Ahn, Dong Won Shin, Sun Young Yum, Richard Walton, Luis Mendez. 2011. A Randomized, Open-Label Assessment of Response to Various Doses of Atomoxetine in Korean Pediatric Outpatients with Attention-Deficit/Hyperactivity Disorder. Psychiatry Investigation 8:2, 141. [CrossRef]

3. J BIEDERMAN, T SPENCER. 2008. Psychopharmacological Interventions. Child and Adolescent Psychiatric Clinics of North America 17:2, 439-458. [CrossRef]

4. Jackie Y. W. Cheng, Ronald Y. L. Chen, John S. N. Ko, Emil M. L. Ng. 2007. Efficacy and safety of atomoxetine for attention-deficit/hyperactivity disorder in children and adolescentsmeta-analysis and meta-regression analysis. Psychopharmacology 194:2, 197-209. [CrossRef]

5. Joachim F Wernicke, Karen Chilcott Holdridge, Ling Jin, Timothy Edison, Shuyu Zhang, Mark E Bangs, Albert J Allen, Susan Ball, David Dunn. 2007. Seizure risk in patients with attentiondeficit-hyperactivity disorder treated with atomoxetine. Developmental Medicine \& Child Neurology 49:7, 498-502. [CrossRef]

6. Neil Easton, Fiona Marshall, Kevin Fone, Charles Marsden. 2007. Atomoxetine produces changes in cortico-basal thalamic loop circuits: Assessed by phMRI BOLD contrast. Neuropharmacology 52:3, 812-826. [CrossRef]

7. 2007. Atomoxetina: luces y sombras. Psiquiatría Biológica 14:1, 13-23. [CrossRef]

8. Yufeng Wang, Yi Zheng, Yasong Du, Dong H. Song, Yee-Jin Shin, Soo C. Cho, Bung N. Kim, Dong H. Ahn, Maria E. Marquez-Caraveo, Haitao Gao, David W. Williams, Louise R. Levine. 2007. Atomoxetine versus methylphenidate in paediatric outpatients with attention deficit hyperactivity disorder: a randomized, double-blind comparison trial. Australian and New Zealand Journal of Psycbiatry 41:3, 222-230. [CrossRef]

9. Donna AntonucciNeurochemistry of ADHD 293-310. [CrossRef]

10. Marcialee Ledbetter. 2006. Atomoxetine: a novel treatment for child and adult ADHD. Neuropsychiatric Disease and Treatment 2:4, 455-466. [CrossRef]

11. L. EUGENE ARNOLD, MICHAEL G. AMAN, AMELIA M. COOK, ANDREA N. WITWER, KRISTY L. HALL, SUSAN THOMPSON, YASER RAMADAN. 2006. Atomoxetine for Hyperactivity in Autism Spectrum Disorders: Placebo-Controlled Crossover Pilot Trial. Journal of the American Academy of Child \& Adolescent Psychiatry 45:10, 1196-1205. [CrossRef]

12. M. Beane, R.T. Marrocco. 2004. Norepinephrine and acetylcholine mediation of the components of reflexive attention: implications for attention deficit disorders. Progress in Neurobiology 74:3, 167-181. [CrossRef]

13. T SPENCER, J BIEDERMAN, T WILENS. 2004. Nonstimulant treatment of adult attentiondeficit/hyperactivity disorder. Psychiatric Clinics of North America 27:2, 373-383. [CrossRef]

14. J Caballero. 2003. Atomoxetine hydrochloride for the treatment of attention-deficit/hyperactivity disorder. Clinical Therapeutics 25:12, 3065-3083. [CrossRef]

15. Norman E. Alessi, Scott Spalding. 2003. ATOMOXETINE AND PREGNANCY. Journal of the American Academy of Child \& Adolescent Psychiatry 42:8, 883-884. [CrossRef] 
16. Damian M. Hughes, Marietta M. Cunningham, Susan E. Libretto. 2002. Risperidone in Children and Adolescents with Autistic Disorder and Aggressive Behaviour. The British Journal of Development Disabilities 48:95, 113-122. [CrossRef]

17. Dave Coghill. 2002. Evidence-based psychopharmacology for children and adolescents. Current Opinion in Psychiatry 15:4, 361-368. [CrossRef]

18. 2001. Current Awareness in human psychopharmacology. Human Psychopharmacology: Clinical and Experimental 16:8, 647-656. [CrossRef] 